\section{Educación Virtual basada en Tecnologías DE INFORMACIÓN}

Recepción: Noviembre de 2004 / Aceptación: Diciembre 2004
(1) Roberto Eyzaguirre Tejada

(2) Víctor Pérez Quispe

(3) Rosmeri Mayta Huatuco

(4) Edgar Ruiz Lizama

(5) Ezzard Álvarez Díaz

\section{RESUMEN}

El artículo presenta un módulo de educación virtual para la Facultad de Ingeniería Industrial. Para su elaboración se utilizó herramientas como el MySQL, PHP, Apache, HTML y Moodle; a fin de establecer un sistema multimedial interactivo que enriquezca el proceso de enseñanza-aprendizaje en la Unidad de Postgrado y el Centro de Extensión Universitaria y Proyección Social (CEUPS), logrando beneficios mutuos para la Universidad y la comunidad en general.

Palabras Claves: Educación virtual. Enseñanza multimedia. Aprendizaje interactivo.

Virtual Education Based UPON INFORMATION TeChNOLOGIES ABSTRACT

This article presents a virtual education module for the Faculty of Industrial Engineering. Some tools such as MySQL, PHP, Apache, HTMLy Moodle were used for its making. The purpose was to set an interactive multimedia system that enriches the teaching-learning process in the Post-Graduate Unit as well as in the Center of University Extension and Social Projection (CEUPS), thus obtaining reciprocal profits for both the University and the community.

Key Words: Virtual education. Multimedia teaching. Interactive learning.

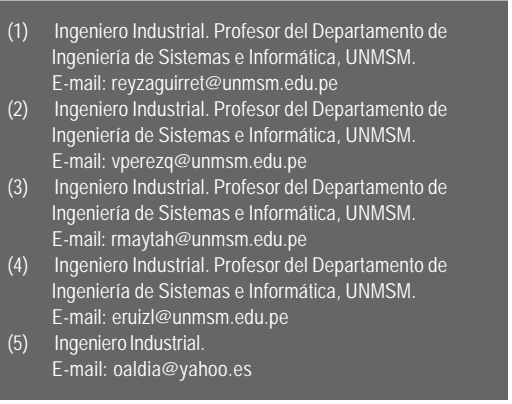

\section{INTRODUCCIÓN}

La educación virtual como "concepto" ha generado bastantes discusiones en el marco social educativo. Muchos la han catalogado como una enseñanza bajo fantasías, descontextualizada, otros arguyen la formación única por Internet. La educación virtual es un sistema y modalidad educativa que surge de la necesidad propia de la educación y tecnología educativa mediante la cual se pretende satisfacer las necesidades de aquellos que no tienen la posibilidad de asistir de modo presencial a la institución educativa.

En los últimos tiempos, las instituciones educativas vienen implementando herramientas que favorecen la educación virtual, por otro lado las tecnologías de información coadyuvan grandemente con ese propósito. Al respecto, el software libre proporciona módulos que permiten al usuario (administrador) la adecuación o modificación de estos de acuerdo a las necesidades particulares de la institución. Dichos módulos están en constante evolución, pues, un gran número de usuarios y desarrolladores de sistemas aportan a su mejora constante.

En este contexto, la creciente oferta de cursos por más universidades y la demanda cada vez mayor, hace necesario el ingreso de la Facultad de Ingeniería Industrial de la Universidad Nacional Mayor de San Marcos a este mercado, a través de la Unidad de Postgrado y el Centro de Extensión Universitaria y Proyección Social - CEUPS.

\section{OBJETIVOS}

El proyecto, tiene como objetivo satisfacer las necesidades de capacitación para los profesionales, a través de la Unidad de Postgrado, así como a todos aquellos que deseen capacitarse en los cursos que se imparten en el CEUPS, y que no tienen la posibilidad de asistir al dictado de estos por diferentes razones tales como:

- Ubicación geográfica de los potenciales estudiantes, distante a los centros de estudios.

- Horario de trabajo incompatible con los horarios de los centros de estudio.

- La necesidad de graduados que buscan su actualización o mejoramiento, sin que ello signifique abandonar su contexto laboral social y familiar. 


\section{ANTECEDENTES}

Según estudios la educación a distancia organizada se remonta al siglo XVIII con un anuncio publicado en 1828 por la Gaceta de Boston, en donde se refería a un material autoinstructivo para ser enviado a los estudiantes con posibilidad de tutorías por correspondencia. En 1840 Isaac Pitman organizó en Inglaterra un intento rudimentario de educación por correspondencia.

En Europa Occidental y América del Norte la educación a distancia empezó en las urbes industriales del siglo XIX con el fin de atender a las minorías, que por diferentes motivos, no asistían a escuelas ordinarias.

Al finalizar la segunda guerra mundial se produjo una expansión de esta modalidad. En la década de los ' 60 y ' 70 se ha dado una marcada expansión de la educación a distancias, tanto en el terreno práctico así como el teórico. Entre 1960 y 1975 se fundaron en África más de 20 instituciones de educación a distancia. En el '70 la Universidad de Wisconsin implementó un sistema y pocos años más tarde empezó con la emisión de videos. A partir de esa fecha la educación a distancia se vio favorecida por el uso de la TV y la radio pública, un claro ejemplo fue la Universidad Abierta del Reino Unido. Entre 1972 y 1980 en Australia el número de instituciones a distancia pasó de 15 a 48. Sin embargo es en los países industrializados como Canadá, Inglaterra, Alemania, Estados Unidos y Japón donde se dió mayor valor a esta modalidad.

Desde 1990 los desarrollos tecnológicos de las PC's cuentan con la posibilidad de integrar elementos multimedia: video, audio, textos, imágenes y realidad virtual. Al mismo tiempo la mejora de la transmisión de la comunicación mediante la banda ancha ha permitido la utilización de nuevos recursos didácticos, como el video en tiempo real, trabajo colaborativo, foros de discusión sincrónica y asincrónica.

\section{LA EDUCACIÓN A DISTANCIA EN EL PERÚ}

Se viene trabajando en la Educación a Distancia en las siguientes instituciones:

- En la Universidad San Ignacio de Loyola que ha instalado un aula virtual para el dictado de clases a su instituto en Trujillo.

- En la Tecsup, que ha implantado sus clases a distancia.

- En la UNI con su proyecto Tele@duca viene desarrollando cursos empleando el learning Space para luego desarrollar la Universidad virtual.

- En la Pontificia Universidad Católica del Perú se viene dictando cursos a distancia.

\section{ÁMBITOS DE ACTUACIÓN Y ALGUNOS EJEM- PLOS DE INICIATIVAS EXISTENTES}

Las nuevas tecnologías de la información y la comunicación están propiciando un cambio cuantitativo y cualitativo en los modos y costumbres sociales, relaciones profesionales y empleo del ocio. Los datos más recientes (ver cuadros 1, 2, 3 y 4) constatan los siguientes crecimientos e índices de penetración por continentes.

\section{Cuadro 1. Estadísticas mundiales del Internet y de población (en permanente actualización)}

\begin{tabular}{|l|r|r|r|r|r|r|}
\hline Regiones & $\begin{array}{c}\text { Población } \\
\text { ( 2004 Est.) }\end{array}$ & $\begin{array}{c}\text { Usuarios } \\
\text { (año 2000) }\end{array}$ & $\begin{array}{c}\text { Usuarios } \\
\text { (dato } \\
\text { más } \\
\text { reciente) }\end{array}$ & $\begin{array}{c}\text { Crecimiento } \\
\text { ( 2000-2004) }\end{array}$ & $\begin{array}{c}\text { \% Población } \\
\text { (Penetración) }\end{array}$ & $\begin{array}{c}\text { (\%) de } \\
\text { Usuarios }\end{array}$ \\
\hline África & $893,197,200$ & $4,514,400$ & $12,937,100$ & $186.6 \%$ & $1.4 \%$ & $1.6 \%$ \\
Asia & $3,607,499,800$ & $114,303,000$ & $257,898,314$ & $125.6 \%$ & $7.1 \%$ & $31.7 \%$ \\
Europa & $730,894,078$ & $103,096,093$ & $230,886,424$ & $124.0 \%$ & $31.6 \%$ & $28.4 \%$ \\
Oriente Medio & $258,993,600$ & $5,284,800$ & $17,325,900$ & $227.8 \%$ & $6.7 \%$ & $2.1 \%$ \\
Norte América & $325,246,100$ & $108,096,800$ & $222,165,659$ & $105.5 \%$ & $68.3 \%$ & $27.3 \%$ \\
Latinoamérica/Caribe & $541,775,800$ & $18,068,919$ & $55,930,974$ & $209.5 \%$ & $10.3 \%$ & $6.9 \%$ \\
Oceanía & $32,540,909$ & $7,619,500$ & $15,787,221$ & $107.2 \%$ & $48.5 \%$ & $1.9 \%$ \\
TOTAL MUNDIAL & $\mathbf{6 , 3 9 0 , 1 4 7 , 4 8 7}$ & $\mathbf{3 6 0 , 9 8 3 , 5 1 2}$ & $\mathbf{8 1 2 , 9 3 1 , 5 9 2}$ & $\mathbf{1 2 5 . 2} \%$ & $\mathbf{1 2 . 7} \%$ & $\mathbf{1 0 0 . 0} \%$
\end{tabular}

NOTAS: (1) Las estadísticas de Usuarios del Internet fueron actualizadas en Octubre 8 del 2.004. (2) Las cifras en detalle para cada región y país pueden verse dando un clic sobre la región correspondiente. (3) Las cifras de población se basan en los datos actuales de gazetteer.de. (4) Las cifras de usuarios mas recientes corresponden a Nielsen//NetRatings, ITU, NIC's, ISP's y otras fuentes confiables. (5) Las cifras de crecimiento fueron determinadas comparando el dato de usuarios actuales de Internet con los datos del año 2.000 de las estadísticas de ITU. (6) Se autoriza la reproducción de estas tablas, siempre y cuando se cite a www.ExitoExportador.com como la fuente original y se establezca un enlace activo. 
Cuadro 2. Los 10 países lideres en el Internet por tener mayor número de usuarios

\begin{tabular}{|c|c|c|c|c|c|c|}
\hline $\mathbf{N}^{\circ}$ & País o Región & $\begin{array}{l}\text { Usuarios (dato } \\
\text { más reciente) }\end{array}$ & $\begin{array}{l}\text { Población } \\
\text { (2004 Est.) }\end{array}$ & $\begin{array}{l}\text { \% Población } \\
\text { (Penetración) }\end{array}$ & $\begin{array}{l}\text { Fecha dato } \\
\text { más reciente }\end{array}$ & $\begin{array}{c}\text { (\%) de } \\
\text { Usuarios }\end{array}$ \\
\hline 1 & Estados Unidos & $201,661,159$ & $293,271,500$ & $68.8 \%$ & Nielsen//NR Ago/04 & $24.8 \%$ \\
\hline 2 & China & $87,000,000$ & $1,288,307,100$ & $6.8 \%$ & CNNIC Jun/04 & $10.7 \%$ \\
\hline 3 & Japón & $66,763,838$ & $127,853,600$ & $52.2 \%$ & Nielsen//NR Ago/04 & $8.3 \%$ \\
\hline 4 & Alemania & $47,182,628$ & $82,633,200$ & $57.1 \%$ & Nielsen//NR Ago/04 & $5.8 \%$ \\
\hline 5 & Reino Unido & 34.874 .469 & 59.595 .900 & $58.5 \%$ & Nielsen//NR Ago/04 & $4.3 \%$ \\
\hline 6 & Corea del Sur & $30,670,000$ & $49,131,700$ & $62,4 \%$ & KRNIC Jun/04 & $3.8 \%$ \\
\hline 7 & Italia & $28,610,000$ & $57,987,100$ & $49.3 \%$ & $\mathrm{C}+\mathrm{I}+\mathrm{A}-\mathrm{Dic} / 03$ & $3.5 \%$ \\
\hline 8 & Francia &, 522 & 200 & $40.6 \%$ & Nielsen//NR Ago/04 & $3.0 \%$ \\
\hline 9 & Canadá & $20,450,000$ & $31,846,900$ & $64.2 \%$ & $\mathrm{C}+\mathrm{I}+\mathrm{A}-\mathrm{Dic} / 03$ & $2.5 \%$ \\
\hline 10 & Brasil & $19,311,854$ & $179,383,500$ & $10.8 \%$ & Nielsen//NR Ago/04 & $2.4 \%$ \\
\hline \multicolumn{2}{|c|}{ Los 10 Países Lideres } & $560,876,470$ & $2,230,021,700$ & $25.2 \%$ & EE - Oct8/04 & $69.0 \%$ \\
\hline \multirow{2}{*}{\multicolumn{2}{|c|}{$\begin{array}{c}\text { Resto del Mundo } \\
\text { Total Mundial Usuarios }\end{array}$}} & $252,055,122$ & $4,160,125,787$ & $6.1 \%$ & EE - Oct8/04 & $31.0 \%$ \\
\hline & & $812,913,592$ & $6,390,147,487$ & $12.7 \%$ & EE - Oct8/04 & $100.0 \%$ \\
\hline
\end{tabular}

NOTAS: (1) Las Estadísticas de Usuarios Lideres del Internet fueron actualizadas en Octubre 8 del 2.004. (2) Para cifras en detalle de cada país o región, de un clic sobre el país correspondiente. (3) Las cifras de población se basan en los datos actuales de gazetteer.de. (4) Las cifras mas recientes de usuarios corresponden a datos de Nielsen//NetRatings, de ITU y otras fuentes confiables. (5) Las cifras de crecimiento se determinaron comparando el dato de usuarios actuales frente al dato para el año 2.000, tomado de las estadísticas delITU. (6) Se autoriza la reproducción de estos datos, siempre y cuando se cite a " www. ExitoExportador.com " como la fuente original y se establezca un enlace activo.

Cuadro 3. Los 10 países que tienen la más alta penetración en el Internet

\begin{tabular}{|c|c|c|c|c|c|}
\hline $\mathbf{N}^{\circ}$ & País o Región & $\begin{array}{l}\text { Penetración } \\
\text { (\% Población) }\end{array}$ & $\begin{array}{l}\text { Usuarios (dato } \\
\text { más reciente) }\end{array}$ & $\begin{array}{l}\text { Población } \\
\text { (2004 Est.) }\end{array}$ & $\begin{array}{c}\text { Fuente del } \\
\text { Dato más Reciente }\end{array}$ \\
\hline 1 & Suecia & $74.6 \%$ & $6.722,576$ & $9,010,700$ & Nielsen//NR Ago/04 \\
\hline 2 & Hong Kong & $72.5 \%$ & $4,878,713$ & $6,727,900$ & Nielsen//NR Ago/04 \\
\hline 3 & Estados Unidos & $68.8 \%$ & 201.661 .159 & 293.271 .500 & Nielsen//NR Ago/04 \\
\hline 4 & Islandia & $66.6 \%$ & 195,000 & 292,800 & ITU - Dic/03 \\
\hline 5 & Holanda & $66.5 \%$ & $10,806,328$ & $16.254,900$ & Nielsen//NR Ago/04 \\
\hline 6 & Australia & $65.9 \%$ & 13.359 .821 & 20.275 .700 & Nielsen//NR Ago/04 \\
\hline 7 & Canadá & $64.2 \%$ & $20,450,000$ & $31,846,900$ & $\mathrm{C}+\mathrm{I}+\mathrm{A}-\mathrm{Dic} / 03$ \\
\hline 8 & Suiza & $63.5 \%$ & $4,717,024$ & $7,433,000$ & Nielsen//NR Ago/04 \\
\hline 9 & Dinamarca & $62.5 \%$ & $3,375,850$ & $5,397,600$ & Nielsen//NR Jun/02 \\
\hline 10 & Corea del Sur & $62.4 \%$ & $30,670,000$ & $49,131,700$ & KRNIC Jun/04 \\
\hline \multicolumn{2}{|c|}{10 Líderes en Penetración } & $66.4 \%$ & $333,845,940$ & $502,738,100$ & EE - Oct8/04 \\
\hline & Resto del Mundo & $8.1 \%$ & 479.085 .652 & 5.887 .409 .387 & EE - Oct8/04 \\
\hline \multicolumn{2}{|c|}{ Total Mundial Usuarios } & $12.7 \%$ & $812,913,592$ & $6,390,147,487$ & EE - Oct8/04 \\
\hline
\end{tabular}

NOTAS: (1) Las Estadísticas de Penetración del Internet fueron actualizadas en Octubre 8, 2004. (2) Para información detallada por país o región, de un clic sobre el país correspondiente. (3) Los datos de población se basan en las cifras actuales de gazetteer.de. (4) Los datos de usuarios provienen de información publicada por Nielsen//NetRatings, ITU, NICs, ISPs y otras fuentes locales. (6) Esta información se puede citar, siempre y cuando se otorgue el debido crédito y se establezca un enlace a www.exitoexportador.com 
Cuadro 4. Usuarios de Internet en América del Sur

\begin{tabular}{|c|c|c|c|c|c|c|}
\hline $\begin{array}{l}\text { AMERICA } \\
\text { DEL SUR }\end{array}$ & $\begin{array}{l}\text { Población } \\
\text { Actual (2004) }\end{array}$ & $\begin{array}{c}\text { Usuarios } \\
(2000)\end{array}$ & $\begin{array}{l}\text { Usuarios } \\
\text { (dato más } \\
\text { reciente) } \\
\end{array}$ & $\begin{array}{l}\text { Crecimiento } \\
(2000-2004)\end{array}$ & $\begin{array}{l}\text { Penetración } \\
\text { (\% Población) }\end{array}$ & $\begin{array}{c}\% \text { de } \\
\text { Usuarios }\end{array}$ \\
\hline Argentina & $37,740,400$ & $2,500,000$ & $4,100,000$ & $64.0 \%$ & $10.9 \%$ & $11.6 \%$ \\
\hline Bolivia & $8,879,600$ & 120,000 & 270,000 & $125.0 \%$ & $3.0 \%$ & $0.8 \%$ \\
\hline Brasil & 183.199 .600 & 5.000 .000 & 20.551 .168 & $311.0 \%$ & $11.2 \%$ & $58.0 \%$ \\
\hline Chile & $15,482,300$ & $1,757,400$ & $3,575,000$ & $103.4 \%$ & $23.1 \%$ & $10.1 \%$ \\
\hline Colombia & $45,299,400$ & 878.000 & $2,000,000$ & $127.8 \%$ & $4.4 \%$ & $5.6 \%$ \\
\hline Ecuador & $12,664,700$ & 180,000 & 537,900 & $198.8 \%$ & $4.2 \%$ & $1.5 \%$ \\
\hline $\begin{array}{l}\text { Guayana } \\
\text { Francesa }\end{array}$ & 196,800 & 2,000 & 2,000 & $0.0 \%$ & $1.0 \%$ & $0.0 \%$ \\
\hline Guyana & 869,100 & 3,000 & 125,000 & $4066,7 \%$ & $14.4 \%$ & $0.4 \%$ \\
\hline Islas Malvinas & 2,300 & & & - & - & $\mathrm{n} / \mathrm{d}$ \\
\hline Paraquay & $5,469,600$ & 20,000 & 100,000 & $400.0 \%$ & $1.8 \%$ & $0.3 \%$ \\
\hline Perú & $27,553,000$ & $2,500,000$ & $2,500,000$ & $0.0 \%$ & $9.1 \%$ & $7.1 \%$ \\
\hline Suriname & 460,300 & 11,700 & 20,000 & $70.9 \%$ & $4.3 \%$ & $0.1 \%$ \\
\hline Uruquay & $3,428,900$ & 370,000 & 400,000 & $8.1 \%$ & $11.7 \%$ & $1.1 \%$ \\
\hline Venezuela & $24,120,500$ & 950,000 & $1,274,400$ & $34.1 \%$ & $5.3 \%$ & $3.6 \%$ \\
\hline TOTAL & $365,366,600$ & $14,292,100$ & $35,455,468$ & $148.1 \%$ & $9.7 \%$ & $100.0 \%$ \\
\hline
\end{tabular}

NOTAS: (1) Las estadísticas de América fueron actualizadas a febrero 29 del 2.004. (2) Para ver las cifras en detalle de cada país de un clic sobre el enlace correspondiente. (3) Las ciras de población se basan en los datos actuales de gazetteer.de. (4) Los datos mas recientes de usuarios corresponden a datos de Nielsen-NetRatings, ITU, NICs, ISPs y otras fuentes confiables. (5) Las cifras de crecimiento se determinaron comparando el numero actual de usuarios con el dato del año 2.000 , tomado de las estadísticas del ITU. (6) Se autoriza la reproducción de estos datos, siempre y cuando se cite a " ExitoExportador.com " como la fuente original y se establezca un enlace.

\section{MARCO CONCEPTUAL}

\section{¿Qué es la educación virtual?}

La UNESCO (1998), la define como «entornos de aprendizajes que constituyen una forma totalmente nueva, en relación con la tecnología educativa(...) un programa informático - interactivo de carácter pedagógico que posee una capacidad de comunicación integrada. Son una innovación relativamente reciente y fruto de la convergencia de las tecnologías informáticas y de telecomunicaciones que se ha intensificado durante los últimos diez años».

Es decir, la educación virtual enmarca la utilización de las nuevas tecnologías, hacia el desarrollo de metodologías alternativas para el aprendizaje de alumnos de poblaciones especiales que están limitadas por su ubicación geográfica, la calidad de docencia y el tiempo disponible. Es aquella que involucra cualquier medio electrónico de comunicación, incluyendo la videoconferencia y la audioconferencia. En sentido más específico, la educación virtual significa enseñar y aprender a través de computadoras en red.

La Facultad de Ingeniería Industrial para este proyecto ha definido a la educación virtual como una modalidad que permite el acto educativo mediante el uso de Internet y video conferencias. Este proceso de for- mación es autodirigido por el mismo estudiante, apoyado por material elaborado por la Unidad de Postgrado y/o CEUPS, en una situación en que estudiantes y profesores se encuentran separados físicamente y sólo se relacionan de manera presencial ocasionalmente.

Principios de la Educación Virtual

La educación virtual está basada en los siguientes principios:

- La autoeducación

- La autoformación

- La desterritorialización

- La descentralización

- La virtualización

- La tecnologización

- La sociabilidad virtual

\section{METODOLOGÍA DE LA EDUCACIÓN VIRTUAL}

La metodología responde al cómo enseñar y aprender. Y en cada modelo de educación virtual se destaca la metodología como base del proceso. A continuación se destacan los dos métodos más sobresalientes: el método sincrónico y asincrónico. 


\section{Método Sincrónico}

Son aquellos en el que el emisor y el receptor del mensaje en el proceso de comunicación operan en el mismo marco temporal; es decir, para que se pueda transmitir dicho mensaje es necesario que las dos personas estén presentes en el mismo momento.

Estos recursos sincrónicos se hacen verdaderamente necesarios como agentes socializadores, imprescindible para que el alumno que estudia en la modalidad virtual no se sienta aislado. Son: Videoconferencias con pizarra, audio o imágenes como el netmeeting de Internet, chat, chat de voz, audio y asociación en grupos virtuales.

\section{Método Asincrónico}

Transmiten mensajes sin necesidad de coincidir entre el emisor y receptor en la interacción instantánea. Requieren necesariamente de un lugar físico y lógico (como un servidor, por ejemplo) en donde se guardarán y tendrán también acceso a los datos que forman el mensaje.

Son más valiosos para su utilización en la modalidad de educación a distancia, ya que el acceso en forma diferida en el tiempo de la información; y se hace absolutamente necesario por las características especiales que presentan los alumnos que estudian en esta modalidad virtual (limitación de tiempos, cuestiones familiares y laborales, etc.). Son un buen ejemplo: email, foros de discusión, www, textos, gráficos animados, audio, Cd's interactivos, video, casettes, etc.

\section{HERRAMIENTAS PARA EL DESARROLLO DEL MÓDULO DE EDUCACIÓN VIRTUAL EN LA FACULTAD DE INGENIERÍA INDUSTRIAL}

A continuación se presentan las principales características de las herramientas utilizadas para el desarrollo del módulo de educación virtual:

\section{MySQL}

MySQL es un servidor de bases de datos multiusuario y el lenguaje de bases de datos más popular y estandarizado del mundo. Además, es el más rápido en entornos web.

MySQL es una implementación cliente/servidor que consiste en un dominio mysqld y varios programas clientes y librerías. Tiene como principales virtudes su gran velocidad, robustez y facilidad de uso.

MySQL soporta muchos lenguajes de programación distintos como: C, C++, Eiffel, Java, Perl, PHP, Python y TCL. También tiene la opción de protección mediante contraseña, la cual es flexible y segura.

\section{PHP}

PHP, acrónimo de "PHP: Hypertext Preprocessor", es un lenguaje "Open Source" interpretado de alto nivel, especialmente pensado para desarrollos web y el cual puede ser embebido en páginas HTML. La mayoría de su sintaxis es similar a C, Java y Perl y es fácil de aprender.

La meta de este lenguaje, es permitir escribir a los creadores de páginas web, páginas dinámicas de una manera rápida y fácil, aunque se pueda hacer mucho más con PHP.

\section{Apache}

Es un servidor en el que se alojan las páginas webs que se suelen ver en internet. El servidor Apache generalmente es el más usado en todos los sistemas Unix (Linux, Solaris), ya que es muy robusto, además de muy potente. También existe una versión especialmente diseñada para Windows aunque presenta una menor reputación y aceptación.

\section{Moodle}

La palabra Moodle es un acrónimo de Modular ObjectOriented Dynamic Learning Environment (Entorno de Aprendizaje Dinámico Orientado a Objetos y Modular). Moodle es un paquete de software para la creación de cursos y sitios Web basados en Internet. Es un proyecto en desarrollo diseñado para dar soporte a un marco de educación.

Moodle se distribuye gratuitamente como software libre (bajo la Licencia pública GNU). Moodle puede funcionar en cualquier ordenador en el que pueda correr PHP, y soporta varios tipos de bases de datos (en especial MySQL).

Moodle está constituido por:

- 6,744 archivos, 667 carpetas.

- $26,1 \mathrm{Mb}(27,403,621$ bytes).

- 2,142 archivos son programas en php.

- 3,839 archivos son páginas en html.

- Consta de una base de datos en mysql con 97 tablas.

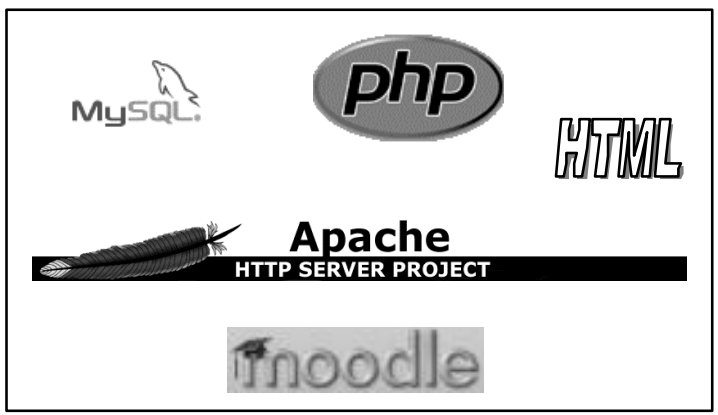

Figura 1. Herramientas utilizadas en el desarrollo del módulo 


\section{CARACTERÍSTICAS DEL MOODLE}

Moodle es un producto activo y en evolución. A continuación se enumeran algunas de sus muchas características:

\section{Diseño General}

- Promueve una pedagogía constructivista social (colaboración, actividades, reflexión crítica, etc.).

- Apropiada para el $100 \%$ de las clases en línea, así como también para complementar el aprendizaje presencial.

- Tiene una interfaz de navegador de tecnología sencilla, ligera, eficiente, y compatible.

- Es fácil de instalar en casi cualquier plataforma que soporte PHP. Sólo requiere que exista una base de datos (y la puede compartir).

- Con su completa abstracción de bases de datos, soporta las principales marcas de bases de datos (excepto en la definición inicial de las tablas).

- La lista de cursos muestra descripciones de cada uno de los cursos que hay en el servidor, incluyendo la posibilidad de acceder como invitado.

- Los cursos pueden clasificarse por categorías y también pueden ser buscados - un sitio Moodle puede albergar miles de cursos.

- Se ha puesto énfasis en una seguridad sólida en toda la plataforma. Todos los formularios son revisados, las cookies encriptadas, etc.

- La mayoría de las áreas de introducción de texto (recursos, mensajes de los foros, entradas de los diarios, etc.) pueden ser editadas usando el editor HTML, tan sencillo como cualquier editor de texto de Windows.

\section{Administración del Sitio}

- El sitio es administrado por un usuario administrador, definido durante la instalación.

- Los "temas" permiten al administrador personalizar los colores del sitio, fuentes, presentación, etc., para ajustarse a sus necesidades.

- Pueden añadirse nuevos módulos de actividades a los ya instalados en Moodle.

- Los paquetes de idiomas permiten una localización completa de cualquier idioma. Estos paquetes pueden editarse usando un editor integrado. Actualmente hay paquetes de idiomas para 43 idiomas.

- El código está escrito de forma clara en PHP bajo la licencia GPL, fácil de modificar para satisfacer sus necesidades.

\section{Administración de Usuarios}

- Los objetivos son reducir al mínimo el trabajo del administrador, manteniendo una alta seguridad.
- Soporta un rango de mecanismos de autenticación a través de módulos de autenticación, que permiten una integración sencilla con los sistemas existentes.

- Método estándar de alta por correo electrónico: los estudiantes pueden crear sus propias cuentas de acceso. La dirección de correo electrónico se verifica mediante confirmación.

- Método LDAP: las cuentas de acceso pueden verificarse en un servidor LDAP. El administrador puede especificar qué campos usar.

- IMAP, POP3, NNTP: las cuentas de acceso se verifican contra un servidor de correo o de noticias (news). Soporta los certificados SSL y TLS.

- Base de datos externa: Cualquier base de datos que contenga al menos dos campos puede usarse como fuente externa de autenticación.

- Cada persona necesita sólo una cuenta para todo el servidor. Por otra parte, cada cuenta puede tener diferentes tipos de acceso.

- Una cuenta de administrador controla la creación de cursos y determina los profesores, asignando usuarios a los cursos.

- Una cuenta como autor de curso permite sólo crear cursos y enseñar en ellos.

- Los profesores pueden tener los privilegios de edición quitados para que no puedan modificar el curso (p.e. para tutores a tiempo parcial).

- Seguridad: los profesores pueden añadir una "clave de acceso" para sus cursos, con el fin de impedir el acceso de quienes no sean sus estudiantes. Pueden transmitir esta clave personalmente o a través del correo electrónico personal, etc.

- Los profesores pueden inscribir a los alumnos manualmente si lo desean.

- Los profesores pueden dar de baja a los estudiantes manualmente si lo desean, aunque también existe una forma automática de dar de baja a los estudiantes que permanezcan inactivos durante un determinado período de tiempo (establecido por el administrador).

- Se anima a los estudiantes a crear un perfil en línea de sí mismos, incluyendo fotos, descripción, etc. De ser necesario, pueden esconderse las direcciones de correo electrónico.

- Cada usuario puede especificar su propia zona horaria, y todas las fechas marcadas en Moodle se traducirán a esa zona horaria (las fechas de escritura de mensajes, de entrega de tareas, etc.).

- Cada usuario puede elegir el idioma que se usará en la interfaz de Moodle (inglés, francés, alemán, español, portugués, etc.).

Administración de Cursos

- Un profesor sin restricciones tiene control total 
sobre todas las opciones de un curso, incluido el restringir a otros profesores.

- Se puede elegir entre varios formatos de curso tales como semanal, por temas o el formato social, basado en debates.

- Ofrece una serie flexible de actividades para los cursos: foros, diarios, cuestionarios, recursos, consultas, encuestas, tareas, chats y talleres.

- En la página principal del curso se pueden presentar los cambios ocurridos desde la última vez que el usuario entró en el curso, lo que ayuda a crear una sensación de comunidad.

- La mayoría de las áreas para introducir texto (recursos, envío de mensajes a un foro, entradas en el diario, etc.) pueden editarse usando un editor HTML WYSIWYG integrado.

- Todas las calificaciones para los foros, diarios, cuestionarios y tareas pueden verse en una única página ( $y$ descargarse como un archivo con formato de hoja de cálculo).

- Registro y seguimiento completo de los accesos del usuario. Se dispone de informes de actividad de cada estudiante, con gráficos y detalles sobre su paso por cada módulo (último acceso, número de veces que lo ha leído) así como también de una detallada "historia" de la participación de cada estudiante, incluyendo mensajes enviados, entradas en el diario, etc. en una sola página.

- Integración del correo. Pueden enviarse por correo electrónico copias de los mensajes enviados a un foro, los comentarios de los profesores, etc. en formato HTML o de texto.

- Escalas de calificación personalizadas - los profesores pueden definir sus propias escalas para calificar foros, tareas y diarios.

- Los cursos se pueden empaquetar en un único archivo zip utilizando la función de "copia de seguridad". Estos pueden ser restaurados en cualquier servidor Moodle.

\section{Módulo de Tareas}

- Puede especificarse la fecha final de entrega de una tarea y la calificación máxima que se le podrá asignar.

- Los estudiantes pueden subir sus tareas (en cualquier formato de archivo) al servidor. Se registra la fecha en que se han subido.

- Se permite enviar tareas fuera de tiempo, pero el profesor puede ver claramente el tiempo de retraso.

- Para cada tarea en particular, puede evaluarse a la clase entera (calificaciones y comentarios) en una única página con un único formulario.

- Las observaciones del profesor se adjuntan a la página de la tarea de cada estudiante y se le envía un mensaje de notificación.
- El profesor tiene la posibilidad de permitir el reenvío de una tarea tras su calificación (para volver a calificarla).

\section{Módulo de Chat}

- Permite una interacción fluida mediante texto síncrono.

- Incluye las fotos de los perfiles en la ventana de Chat.

- Soporta direcciones URL, emoticonos, integración de HTML, imágenes, etc.

- Todas las sesiones quedan registradas para verlas posteriormente, y pueden ponerse a disposición de los estudiantes.

\section{Módulo de Consulta}

- Es como una votación. Puede usarse para votar sobre algo o para recibir una respuesta de cada estudiante (por ejemplo, para pedir su consentimiento para algo).

- El profesor puede ver una tabla que presenta de forma intuitiva la información sobre quién ha elegidoqué.

- Se puede permitir que los estudiantes vean un gráfico actualizado de los resultados.

\section{Módulo Foro}

- Hay diferentes tipos de foros disponibles: exclusivos para los profesores, de noticias del curso y abiertos a todos.

- Todos los mensajes llevan adjunta la foto del autor.

- Las discusiones pueden verse anidadas, por rama, o presentar los mensajes más antiguos o los más nuevosprimeros.

- El profesor puede obligar la suscripción de todos a un foro o permitir que cada persona elija a qué foros suscribirse de manera que se le envíe una copia de los mensajes por correo electrónico.

- El profesor puede elegir que no se permitan respuestas en un foro (por ejemplo, para crear un foro dedicado a anuncios).

- El profesor puede mover fácilmente los temas de discusión entre distintos foros.

- Las imágenes adjuntas se muestran dentro de los mensajes.

- Si se usan las calificaciones de los foros, pueden restringirse a un rango de fechas.

\section{Módulo Diario}

- Los diarios constituyen información privada entre el estudiante y el profesor.

- Cada entrada en el diario puede estar motivada por una pregunta abierta. 
- La clase entera puede ser evaluada en una página con unúnico formulario, por cada entrada particular de diario.

- Los comentarios del profesor se adjuntan a la página de entrada del diario y se envía por correo la notificación.

\section{Módulo Cuestionario}

- Los profesores pueden definir una base de datos de preguntas que podrán ser reutilizadas en diferentes cuestionarios.

- Las preguntas pueden ser almacenadas en categorías de fácil acceso, y estas categorías pueden ser "publicadas" para hacerlas accesibles desde cualquier curso del sitio.

- Los cuestionarios se califican automáticamente, y pueden ser recalificados si se modifican las preguntas.

- Los cuestionarios pueden tener un límite de tiempo a partir del cual no estarán disponibles.

- El profesor puede determinar si los cuestionarios pueden ser resueltos varias veces y si se mostrarán o no las respuestas correctas y los comentarios.

- Las preguntas y las respuestas de los cuestionarios pueden ser mezcladas (aleatoriamente) para disminuir las copias entre los alumnos.

- Las preguntas pueden crearse en HTML y con imágenes.

- Las preguntas pueden importarse desde archivos de texto externos.

- Los cuestionarios pueden responderse varias veces.

- Los intentos pueden ser acumulativos, y acabados tras varias sesiones.

- Las preguntas de opción múltiple pueden definirse con una única o múltiples respuestas correctas.

- Pueden crearse preguntas de respuesta corta (palabras o frases).

- Pueden crearse preguntas tipo verdadero/falso.

- Pueden crearse preguntas de emparejamiento.

- Pueden crearse preguntas aleatorias.

- Pueden crearse preguntas numéricas (con rangos permitidos).

- Pueden crearse preguntas de respuesta incrustada (estilo "cloze") con respuestas dentro de pasajes de texto.

- Pueden crearse textos descriptivos y gráficos.

\section{Módulo Recurso}

- Admite la presentación de cualquier contenido digital, Word, PowerPoint, Flash, vídeo, sonidos, etc.
- Los archivos pueden subirse y manejarse en el servidor, o pueden ser creados sobre la marcha usando formularios web (de texto o HTML).

- Se pueden enlazar contenidos externos en webo incluirlos perfectamente en la interfaz del curso.

- Pueden enlazarse aplicaciones web, transfiriéndoles datos.

Módulo Encuesta

- Se proporcionan encuestas ya preparadas (COLLES, ATTLS) y contrastadas como instrumentos para el análisis de las clases en línea.

- Los informes de las encuestas están siempre disponibles, incluyendo muchos gráficos. Los datos pueden descargarse con formato de hoja de cálculo Excel o como archivo de texto CVS.

- La interfaz de las encuestas impide la posibilidad de que sean respondidas sólo parcialmente.

- A cada estudiante se le informa sobre sus resultados comparados con la media de la clase.

\section{Módulo Taller}

- Permite la evaluación de documentos entre iguales, y el profesor puede gestionar y calificar la evaluación.

- Admite un amplio rango de escalas de clasificación posibles.

- El profesor puede suministrar documentos de ejemplo a los estudiantes para practicar la evaluación.

- Es muy flexible y tiene muchas opciones.

\section{APLICACIÓN EN LA FACULTAD DE INGENIERÍA INDUSTRIAL - UNMSM}

En las figuras 2, 3, 4, 5, 6 y 7 se muestran algunas vistas del módulo de educación virtual aplicado en la Facultad de Ingeniería Industrial de la Universidad Nacional Mayor de San Marcos (UNMSM).

\section{CONCLUSIONES}

La enseñanza a distancia será la forma por excelencia de la actualización de conocimientos del futuro, ya que las transformaciones sociales y económicas se han acelerado y ya no será suficiente para los trabajadores manuales e intelectuales estudiar una profesión u oficio para toda la vida. De esta manera, se estará obligado a reconvertir nuestra especialidad dos y tres veces en el curso de la vida activa y no será posible ir dos y tres veces a la universidad o a una escuela técnica para estudiar esas nuevas carreras y oficios. La única forma para ello será la modalidad no presencial, en horarios al exterior de la 


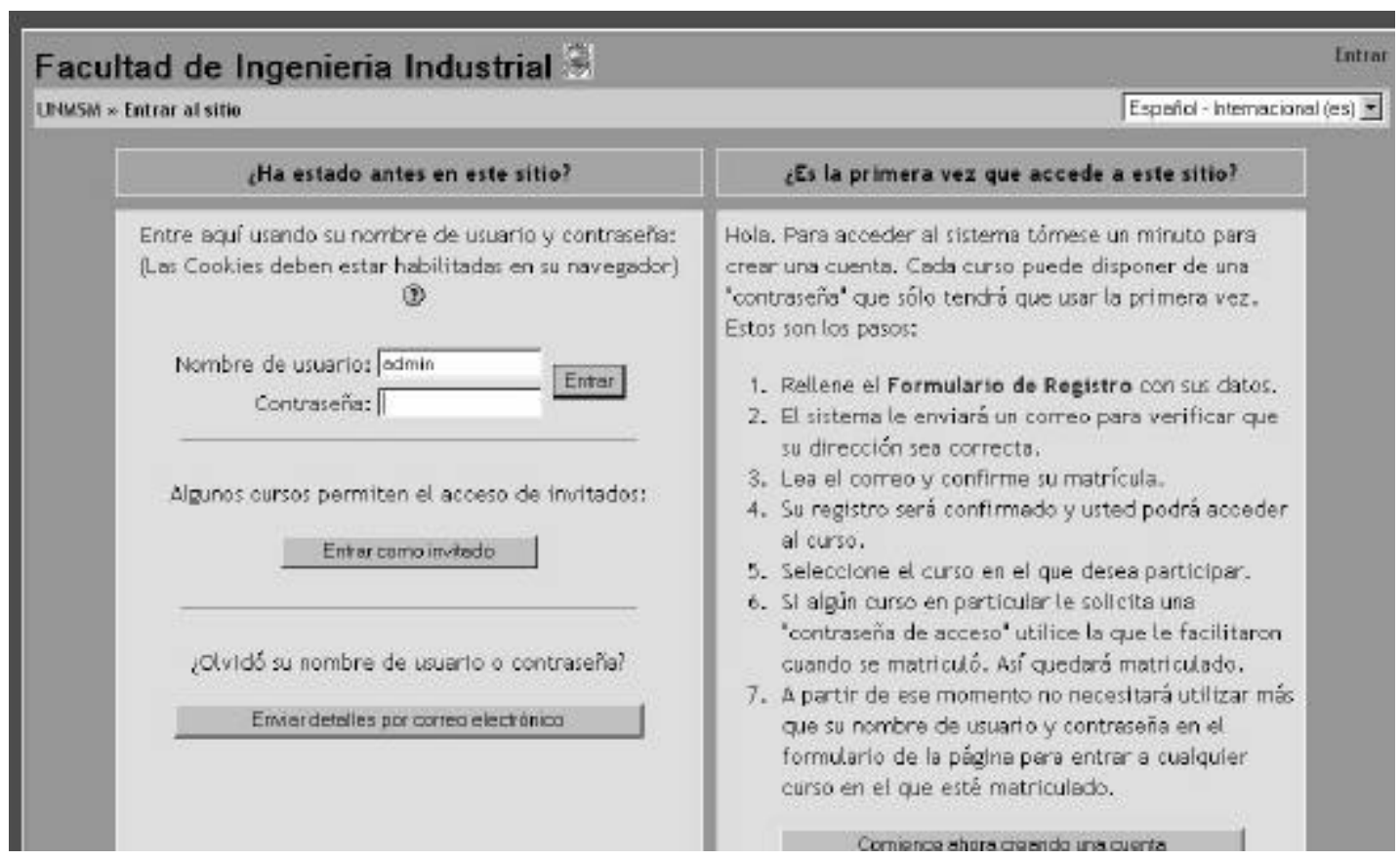

Figura 2. Página principal del administrador

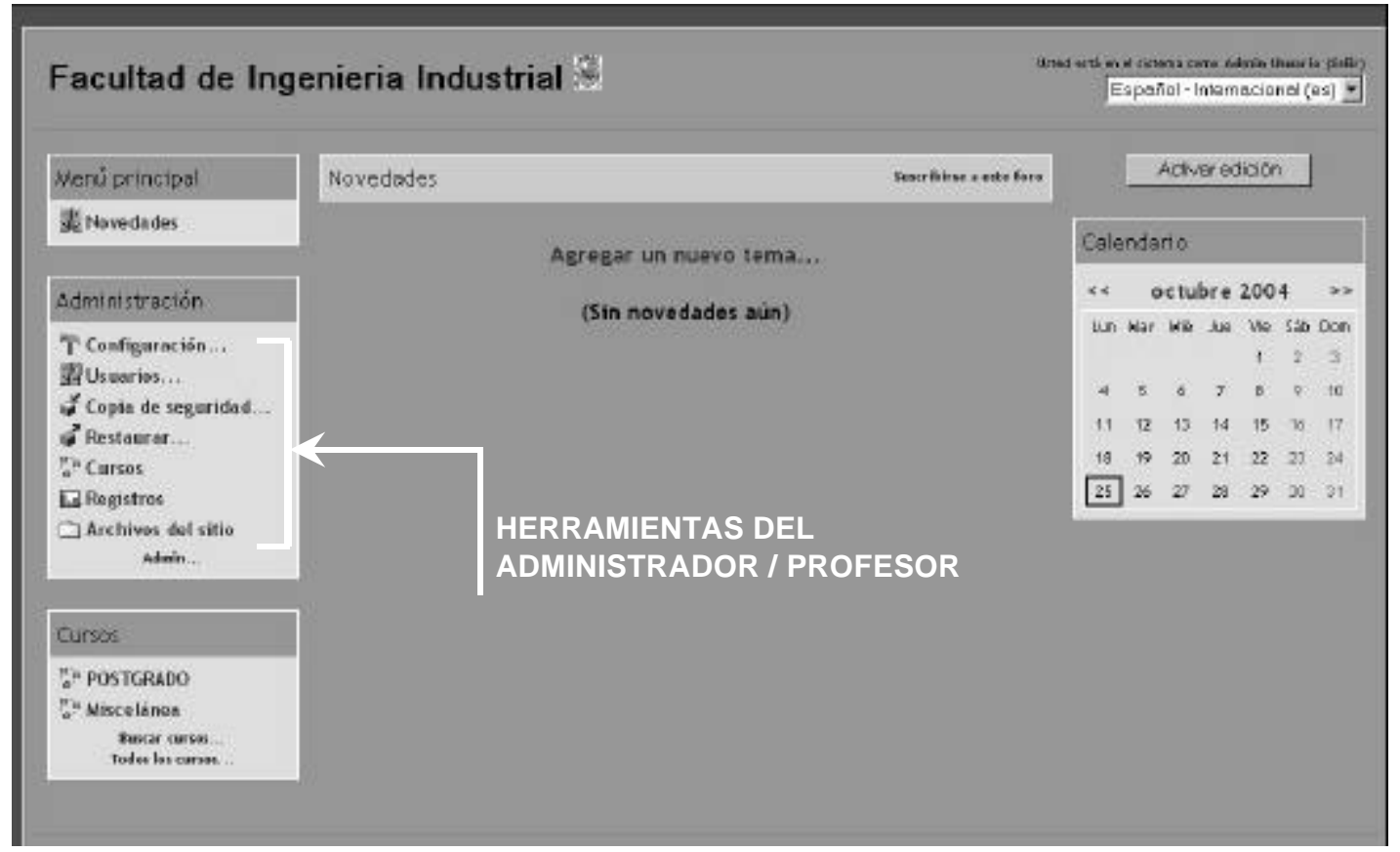

Figura 3. Configuración del programa (parte 1) 


\section{Facultad de Ingenieria Industrial}

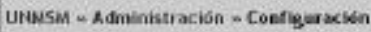

Configuracion

Configuración general Configurar variables que inciden en la operación general del sitio

Configurar al sitio Oefinir el aspecto de la página principal

Tomas Elegir el estilo del sitio (colores, fuentes, etc.)

Idioma Reviser y editar al presente ifioma

Administrar modulos addministror los módulos instolados y sus configuraciones

Bloques twanejar blaques instalados y sus ajustes

Filtros Seleccionar filtros de texto $y$ su configuración

Copia de seguridad Configurer las copias de seguridad automáticas

Ajustes del editor 0efinir ajustes bácicos del editor HTML.

Usted astì mel staterna como Admis Usuacte (5als)

UTWSM

Figura 4. Configuración del programa (parte 2)

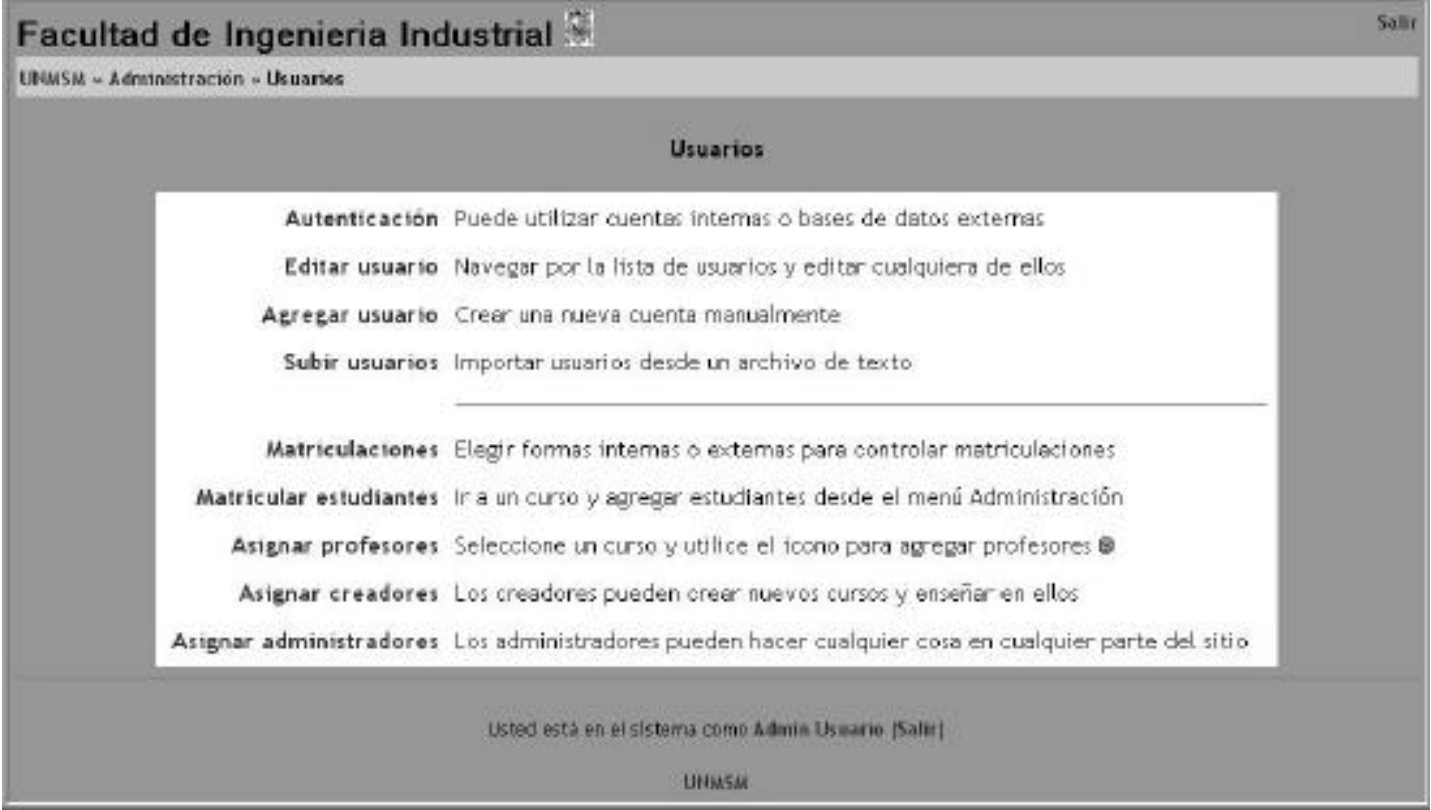

Figura 5. Configuración del programa (parte 3) 


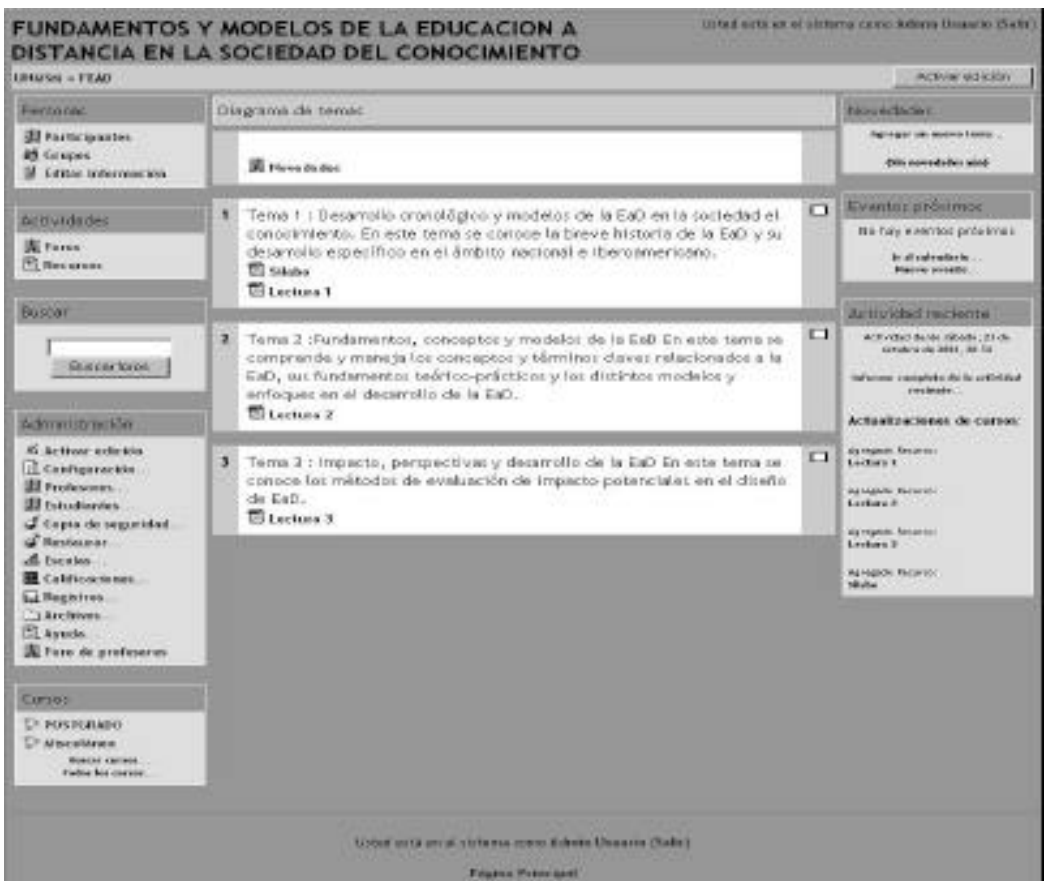

Figura 6. Contenidos (parte 1)

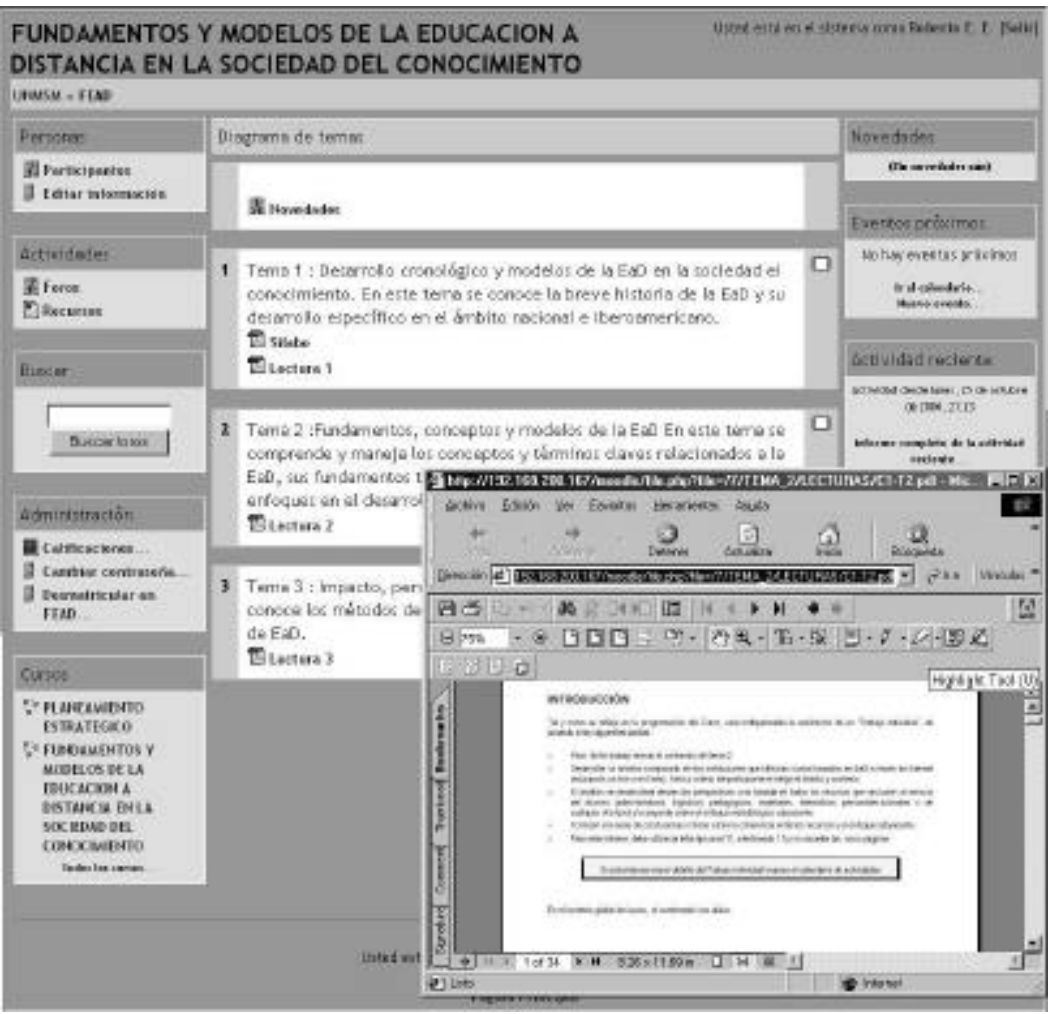

Figura 7. Contenidos (parte 2) 
jornada de trabajo y según los ritmos y posibilidades de cada uno.

El módulo de educación virtual de la Facultad de Ingeniería Industrial atenderá a miles de usuarios sin importar la distancia, el espacio y el tiempo. El uso de este módulo exige un sistema de enseñanza multimedial interactivo, tecnologías computacionales y docentes de «nuevo tipo», que permitan trabajar de manera colaborativa, aportando ideas y opiniones para enriquecer el proceso enseñanza-aprendizaje.

El módulo logra que los estudiantes elaboren y envíen sus asignaciones, proyectos y evaluaciones a través de medios electrónicos permitiendo también las discusiones sincrónicas del grupo, en ambientes virtuales (foros). Como se puede apreciar, este módulo ofrece una gran cantidad de formas para lograr sesiones donde todos los participantes están virtualmentepresentes.

Es necesario mencionar que el módulo puede ser modificado, ya que tiene un lenguaje de código abierto, de acuerdo a las necesidades de la Unidad de Postgrado y CEUPS de la Facultad de Ingeniería Industrial.

\section{BIBLIOGRAFÍA}

1. Barros, Oscar. (1998). Tecnologías de la Informa- ción Base e Integración de las TI: Redes Organizacionales. McGraw-Hill Interamericana de Chile Ltda.

2. Black, Ulises. (1997). Redes de Computadora. Alfa Omega Grupo Editor S.A. de C.V. México.

3. Bustamante, César. (1998). Guía para el Diseñador de Páginas WEB. Grad Perú - Consultorio Informático. Lima, Perú.

4. De Miguel y Platini, M. (1997). Fundamentos y Modelos de Base de Datos. Editorial Rama, Madrid, España.

5. Gil, Ignacio. (1997). Sistemas y Tecnologías de Información para la Gestión. Editorial McGrawHill. España.

6. Holzener, Steven. (2000). La Biblia de Java 2. Ediciones Anaya Multimedia S.A. España.

7. Luna, Ruben. (2000). Trabajando con Flash 5. RITISA Graf S.R.L. Lima, Perú.

8. Serrano Pérez, Jorge. (2000). Programación con $A S P$. Ediciones Anaya Multimedia S.A. España.

9. Zorrilla Serna, Abel. (2000). Modelando Datos con Erwin 4.0. Imprenta Sling E.I.R.L. 